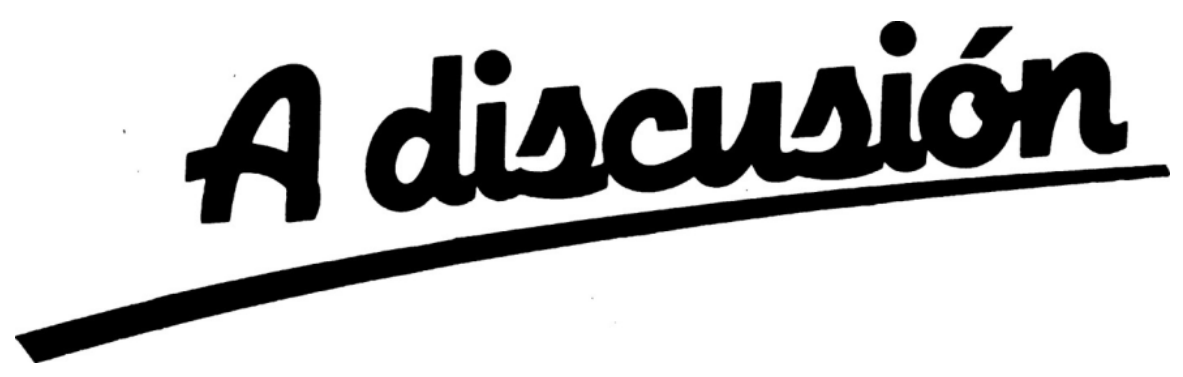

\title{
A MODEL FOR TEAM MANAGERS \\ IN THE PRESENCE OF SELF-SERVING WORKERS*
}

\author{
Brice Corgnet**
}

WP-AD 2007-18

Editor: Instituto Valenciano de Investigaciones Económicas, S.A.

Primera Edición A gosto 2007

Depósito Legal: V-3487-2007

IVIE working papers offer in advance the results of economic research under way in order to encourage a discussion process before sending them to scientific journals for their final publication.

* This paper is a revised version of part of my PhD dissertation at Universidad Carlos III de Madrid under the supervision of Luis Ubeda (University of Alicante). Financial support from IVIE is gratefully acknowledged.

**Universidad de Navarra, email: bcorgnet@unav.es. 


\title{
A MODEL FOR TEAM MANAGERS IN THE PRESENCE \\ OF SELF-SERVING WORKERS
}

\author{
Brice Corgnet
}

\begin{abstract}
We develop a model of team formation in which workers learn about their level of ability. We show that insufficient cooperation may arise as workers learn positively about their own skills. We then build a model for team managers and establish that their objectivity in assessing coworkers' abilities may facilitate cooperation among agents. This is the case because managers are able to design team contracts based on workers' true performances. Our work provides a motive for the existence of team managers in the absence of asymmetry of information.
\end{abstract}




\section{Introduction}

Teamwork has become increasingly popular in organizations since the beginning of the nineties (Dumaine 1990, Osterman 1994, Lawler, Morhman and Ledford 1995, Ichniowski, Shaw and Prennushi 1997) so that understanding the factors leading to team success has become decisive (Stewart 2006). In this paper, we provide a psychological approach to the issue of team formation and team management. In particular, we develop a model in which individuals suffer from self-serving biases. Self-serving biases imply that workers tend to learn positively about their own skills. There exists widespread evidence in the Psychology literature stressing that people learn optimistically about themselves by taking credit for successes while denying responsibility for failures (Bradley 1978, Miller and Ross 1975, Zuckerman 1979). Individuals are inclined to process information distortedly so as to build a positive self-image (Fiske and Taylor 1991, Nisbett and Ross 1980). In addition, there is extensive evidence that people recall their successes better than their failures (Korner 1950, Silverman 1964, Mischel, Ebbesen and Zeiss 1976). This leads individuals to hold excessively positive beliefs about themselves (Greenwald 1980, Svenson 1981 and Cooper, Woo and Dunkelberg 1988). Psychology literature has mostly interpreted biases in inference and attribution as motivational biases. Agents are considered to feel better-off when learning positively about themselves. We account for these motivational biases by assuming that workers are likely to process bad signals about their abilities as if they were good signals.

Various researchers have studied the role of behavioral factors in the context of teams. They have focused on finding possible solutions to free riding arising in teams when efforts of its members are not observable. ${ }^{1}$ Rotemberg (1994) demonstrates how altruism can improve workers' cooperation and welfare when complementarities exist among team members. Kandel and Lazear (1992) show how peer pressure can increase cooperation among workers by stressing how workers can reduce the negative effects of peer pressure by exerting higher levels of efforts. Gervais and Goldstein (2006) find that workers' biased self-perception facilitates cooperation among agents. The argument is that an overconfident agent overestimates his marginal product of effort leading himself and his coworker to exert more effort in the team. The authors show that both the self-confident and the rational workers can benefit from overconfidence.

To analyze team formation we consider a two-period model in which workers jointly decide whether to form a team or work alone. We assume that workers' abilities are unknown, and agents update their beliefs about abilities after receiving a signal at the end of the first period. We show that when workers suffer from self-serving attribution, cooperation among agents is undermined. The negative impact of self-serving biases on team formation is

\footnotetext{
${ }^{1}$ Free riding issues in teams have been studied in numerous papers such as Holmstrom (1982), Itoh (1991) or Che and Yoo (2001).
} 
referred to as the teams inefficiency result.

We then consider how hiring a team manager can improve cooperation among self-serving workers. This helps us shed light on the debate on the efficiency of organizations implementing self-managed teams (Dumaine 1990, Goodman, Devadas and Hughson 1998, Stewart and Barrick 2000). We show that in equilibrium team managers that are capable of observing workers' performances objectively can help improve cooperation among agents. This is the case because team managers are able to design team contracts based on true workers' performances. Managers will permit workers to learn more objectively about their own abilities. In our model, managers are able to learn correctly about workers' performances since they are not involved in choosing the production process. If managers are involved in the production process they may tend to blame workers for insufficient performances rather than challenging the production system that they decided to implement (Repenning and Sterman 2002).

We also show that managers are hired even if observing workers performances is costly. We provide in this paper a psychological motivation for the existence of managers. Asymmetries of information are not necessary in our model to show that team managers can be hired in equilibrium. The manager considered in this paper is not a teamwork supervisor as it is described in Alchian and Demsetz (1972) and Holmstrom (1982). These authors emphasize that in the presence of moral hazard in teams, a supervisor that holds a residual claim on the team outcome can lead workers to exert their optimal level of effort. In our framework, workers' performances are mutually observable. However, individuals may interpret differently the same pieces of information as long as they suffer from self-serving biases. This is the case because workers tend to learn excessively positively about their own level of ability. Our approach implies that the manager has an informational rent since he is able to observe workers' performances objectively. In our model, the manager has private information about individuals' abilities whereas workers do not correctly asses their own performances.

Our framework differs from the ones previously mentioned since it eliminates free riding issues by assuming observability of coworkers' actions. We consider the most favorable case for workers' cooperation by focusing on teams with a sufficiently close level of collaboration such that agents are able to observe each others' performances and actions. Asymmetry of information arises as a consequence of self-serving biases. This is the case since learning biases imply that workers learn differently about their ability and the ability of their partner.

This paper is structured as follows. In the second section, we present the model of team formation and we establish the teams inefficiency result. In Section 3, we develop a model for managers. We discuss our results in Section 4 by emphasizing the empirical implications of our model. 


\section{Team formation and self-serving biases}

\subsection{The team formation framework}

We consider the case of two workers deciding whether to complete an individual or a team project. Examples of such decisions are found in the academia when researchers decide whether to write a single-authored or a coauthored paper. Workers may also be confronted with decisions to form teams in their organizations as in the case of the Koret Corporation described by Hamilton, Nickerson and Owan (2003). We propose to model team formation in a two-period game described as follows. At $t=0$, the two coworkers decide simultaneously whether to undertake the individual or the group project. The team project is undertaken only if both workers agree to do so. At the end of the first period the outcome of the project chosen at $t=0$ is observed by both workers. At $t=1$, agents decide whether to continue with the project undertaken in the first period. The outcome associated to the project performed in the second period is observed at $t=2$. Team members do not know neither their own ability to undertake the task nor the ability of their coworker. Workers update their beliefs about abilities at the end of the first period after observing the outcome of the project chosen in the first period. We assume agents are risk neutral so that they select their projects by maximizing expected payoffs. An agent $i \in\{1 ; 2\}$ when working alone undertakes a project that is a success [failure] with probability $q_{i}\left[1-q_{i}\right]$ and delivers a payoff $X_{i, t} \equiv G(B<G)$, where $q_{i}$ is defined as Worker $i$ s ability. The subscript $t$ corresponds to time where $t \in\{0 ; 1 ; 2\}$. We drop the time subscript when not necessary. We assume a Beta prior distribution for individual abilities: $q_{i} \sim \operatorname{Beta}(\alpha, \beta)$ and we denote $q^{*}=\frac{\alpha}{\alpha+\beta}$ the mean of this distribution. ${ }^{2-3}$ The outcomes of the two individual projects are assumed to be independent. If workers choose to form a team, they are involved in a project that delivers the following payoff $\gamma\left(X_{1, t}+X_{2, t}\right), \forall t \in\{1 ; 2\}$. The total outcome of the group project is shared according to an allocation rule $\eta \in[0,1]$ so that Workers 1 and 2 get respectively payoffs $\eta \gamma\left(X_{1, t}+X_{2, t}\right)$ and $(1-\eta) \gamma\left(X_{1, t}+X_{2, t}\right)$. The parameter $\gamma$ represents synergies obtained for working in a team. We assume $\gamma$ is known by workers at $t=0$. The absence of synergies corresponds to $\gamma=1$. In that case the total outcome of the team project is the sum of the individual projects outcomes. In addition, we assume the existence of a learning by doing effect such that if workers repeat a project (a team or an individual project) the expected payoffs associated to that project are multiplied by $\phi \geq 1$. We consider no discount factors; the effect of discounting would be to reduce the role of learning about workers' abilities at $t=1 .{ }^{4}$ We

\footnotetext{
${ }^{2}$ The beta prior assumption is convenient since the beta distribution is a conjugate prior for the binomial problem considered here (Box and Tiao 1973). In addition, beta distributions can approximate any reasonably smooth unimodal distribution on [0, 1] (Lee 1997).

${ }^{3}$ Similar results are obtained if we consider workers with different prior abilities.

${ }^{4} \mathrm{~A}$ low discount factor would not be consistent with our aim since we want to consider projects for which learning and then self-attribution biases matter.
} 
discuss the assumptions of our model of team formation as well as possible extensions in Appendix $A$.

\subsection{The benchmark case: the absence of self-serving biases}

We consider an allocation rule under which the share of the group outcome obtained by an individual is equal to his relative ability. The relative ability of Worker $i$ is defined as $\frac{\hat{q}_{i, t}}{\hat{q}_{i, t}+\hat{q}_{j, t}}, i \neq j, \forall(i, j) \in\{1 ; 2\}, \forall t \in\{0 ; 1\}$. We denote $\hat{q}_{i, t}$ the level of ability of Worker $i$ as updated by a Bayesian inferer given information up to time $t$. Under this allocation rule, Worker $i$ 's expected payoffs for a team project undertaken for the first time is $\gamma \hat{q}_{i, t}$. The next proposition shows that, in this case, workers form teams at $t=0$ whenever $\gamma \geq 1 .^{5}$ This result still holds if coworkers' prior abilities are different as long as both workers agree on the priors.

\section{Proposition 1 Under the relative ability allocation rule and in the absence of self-serving biases, teams are formed at $t=0$ whenever $\gamma \geq 1$.}

Our proposition shows that by selecting a splitting rule that depends on updated workers' ability, the maximum level of workers' cooperation is attained. ${ }^{6}$ As a result, we show that the efficient teams outcome (ETO) is attainable in the absence of self-serving biases, where the ETO corresponds to the payoffs obtained by team members when teams are formed at $t=0$ and continued at $t=1$ whenever $\gamma \geq 1$. We call efficient teams equilibrium $(E T E)$ an equilibrium that implements the ETO. A team is called efficient whenever $\gamma \geq 1$.

\subsection{The teams inefficiency result}

In this section we consider that workers suffer from biases in their learning process. Self-serving attribution as it is mentioned in the introduction can be seen as Bayesian learning with imperfect processing of negative signals. Researchers have found that positive personality information is efficiently processed whereas negative personality information is poorly processed (Kuiper and Derry 1982, Kuiper and McDonald 1982, Kuiper et al. 1985). We introduce inference biases by assuming that, with probability $p$, workers process bad signals about their ability as if they were good signals. Our assumption implies a different treatment of bad and good signals. This asymmetry in the learning process is what we call biased self-attribution or self-serving learning.

\footnotetext{
${ }^{5}$ In addition to the subgame-perfect Nash equilibrium considered in Proposition 1, the other subgame-perfect equilibria are as follows. By backward induction we obtain the following equilibria. 1) No workers form teams at $t=1$ and teams are formed for $\gamma \geq \phi$ at $t=0$. 2) No workers form teams at $t=0$ and at $t=1$. 3) Teams are formed at $t=1$ and no teams are formed at $t=0$. These equilibria involve weakly dominated strategies. In addition they involve strategies that prevent any cooperation in at least one of the two periods.

${ }^{6}$ However, one may think of real life examples in which workers are not paid with respect to their relative abilities. In the case of Economics research, credits are shared equally among team members.
} 
Workers are tempted to distort bad signals about their abilities in order to build a positive self-image. Through time, above average effects arise leading workers to see themselves as more talented than their coworkers. The latter effects generate a dispersion in coworkers' beliefs about their own ability and the ability of their coworker. Differences in perceptions about abilities will lead agents to break teams. The learning process that is considered in this section is described in Assumption 1. Workers are assumed to suffer from self-serving biases by mistakenly interpreting bad signals about their abilities. ${ }^{7}$ We consider that agents are aware of their incentives to process information with biases. ${ }^{8}$ At the same time we assume that workers update others' abilities using Bayesian inference. We take $p_{G}\left[p_{B}\right]$ to be the expected probability given information at $t=0$ that $X_{i, 1}=G\left[X_{i, 1}=B\right], \forall i \in\{1 ; 2\}$.

\section{Assumption 1 (Self-serving Learning for sophisticated work- ers)}

We denote $\sigma_{i j}$ Worker $i$ 's perception of Worker $j$ 's performance at $t=$ $1, \forall(i, j) \in\{1 ; 2\}^{2}$. We assume that, with probability $p$, a Worker $i$ perceives his bad performance at $t=1\left(X_{i, 1}=B\right)$ as if it was a good performance $\left(\sigma_{i i}=G\right), \forall i \in\{1 ; 2\} .{ }^{9}$ The updating rule at $t=1$ is described as follows, $\forall i \in\{1 ; 2\}$.

$$
\left[\begin{array}{rl}
E_{i, S}\left[q_{i} \mid \sigma_{i i}=B\right] & \equiv q_{B} \equiv E\left[q_{i} \mid X_{i, 1}=B\right] \\
E_{i, S}\left[q_{i} \mid \sigma_{i i}=G\right] \equiv \hat{q}_{G} \equiv \frac{p p_{B}}{p p_{B}+p_{G}} E\left[q_{i} \mid X_{i, 1}=B\right]+\frac{p_{G}}{p p_{B}+p_{G}} E\left[q_{i} \mid X_{i, 1}=G\right]
\end{array}\right.
$$

A worker updates his coworker's ability using Bayesian inference and correct information processing, that is $\sigma_{i j}=X_{j, 1}, \forall i \neq j$ and $(i, j) \in$ $\{1,2\}^{2}$.

We denote $E_{i, S}$ the expectation of workers suffering from self-serving biases $p .{ }^{10}$ We introduce a subscript $i$ for the expectation of Worker $i$ since when learning biases are present coworkers' expectations may not coincide. We assume that the two coworkers suffer from learning biases. According to our learning process, workers update differently beliefs about their own ability and beliefs about others' abilities. Agents are considered to behave as Bayesian inferers when updating others' abilities but they are assumed to suffer from self-serving biases when updating their own ability. There is evidence in the literature in Psychology that individuals see themselves more positively than others see them. For example, Lewinsohn et al. (1980) compared the ratings made by observers and by college students themselves about personality characteristics like friendliness, warmth and assertiveness of students involved in

\footnotetext{
${ }^{7}$ Learning biases can be modeled as a result of errors in information processing or as memory imperfections. However, this distinction between the different origins of learning biases is not central to our results and to their implications.

${ }^{8}$ Bénabou and Tirole (2002) refer to this assumption as metacognition.

${ }^{9}$ Workers' biases are assumed to be independent.

${ }^{10}$ Alternatively, we can consider the case of two agents with different degrees of self-serving attribution: $p_{1} \neq p_{2}$. The results derived below continue to hold taking $p \equiv \operatorname{Max}\left\{p_{1} ; p_{2}\right\}$.
} 


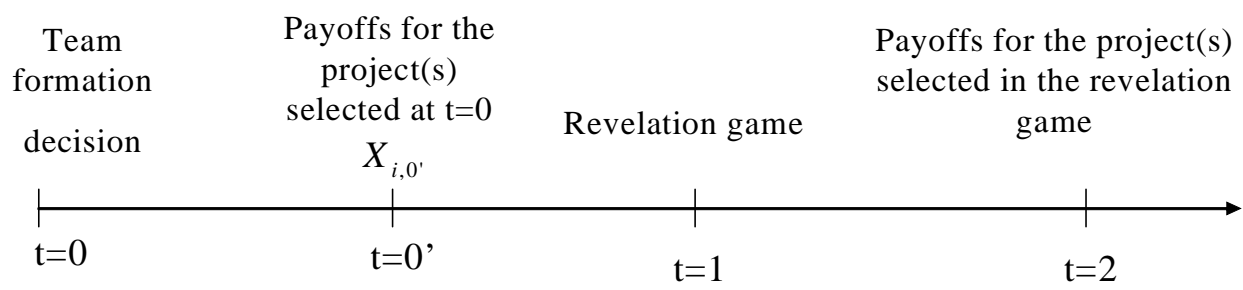

Figure 1: Timeline for the team formation model with self-serving workers.

a group interaction task. They found that self-ratings were significantly more positive than observers' ratings. We consider the case in which team workers do not suffer from learning biases in assessing their coworker's ability.

The self-serving learning process is assumed to be common knowledge. We consider that workers are aware of their incentives to be biased. Workers will try to overcome their biases by recovering the correct signals about their abilities. The inefficiency result captured in Proposition 2 is based on the assumption that workers are unable to recover information about their own ability. This behavior is consistent with Assumptions $2 a$ and $2 b$. In this section, we assess the robustness of the teams inefficiency result by considering sophisticated agents of the type described in Bénabou and Tirole (2002).

We define a contract as the share of the group outcome $\eta_{i}$ distributed to Worker $i$ at $t=1, \forall i \in\{1 ; 2\} .{ }^{11}$ The set of contracts analyzed are budget balanced, that is the group outcome is distributed in its totality to workers $\left(\eta_{1}+\eta_{2}=1\right)$. We consider contracts that can be contingent on coworkers' performances received at $t=1$. The difficulty is that workers' suffering from self-serving biases may disagree about the signals received at $t=1$. To tackle this issue we consider that contracts are contingent on the signals revealed by the agents rather than on the signals effectively observed. We modify the initial framework by introducing a revelation game at $t=1$ after workers have observed their performances on the first period project (Figure 2). ${ }^{12}$ Workers are interested in communicating about their perceived abilities since they know that their coworker is an objective observer of their performances. On aggregate workers have complete information about abilities since Worker 1 [2] knows Worker 2 [1] ability level at $t=1$.

The structure of the revelation game played at $t=1$ is as follows.

At $t=1$ each coworker chooses an action $a_{i} \equiv\left(a_{i 1}, a_{i 2}\right) \forall i \in\{1,2\}$, where $a_{i}$ is a vector of messages that belongs to the set $S$ of possible signals observed

\footnotetext{
${ }^{11}$ The share of the group outcome given to Worker 1 in the first period is not considered further since $\eta_{1}=\frac{1}{2}$ ensures team formation at $t=0$ if team formation is obtained at $t=1$.

${ }^{12} \mathrm{We}$ assume that performances are not verifiable by the court. If performances were verifiable by the court, workers could reach the ETO by asking the court to reveal workers' performances. Evidently, such a process can be costly to workers.
} 
at $t=0$ '. The set $S$ is actually the set of possible types of coworkers. This is the case since the perception of performances by the agents constitutes their private information. ${ }^{13}$

At $t=1^{\prime}$ where $\left.1^{\prime} \in\right] 1,2[$, workers decide either to continue with the project selected at $t=0$ or to undertake the other project. We denote $b_{i} \in$ $B \equiv\{T ; N T\}$, Worker $i$ 's action at $t=1^{\prime}, \forall i \in\{1 ; 2\}$, where $T[N T]$ stands for forming a team [working alone].

The actions of the two agents will determine the share of the group outcome given to the first coworker $(\eta)$ as a function of the revealed signals, that is $\eta \equiv \eta_{1}\left(a_{11}, a_{12}, a_{21}, a_{22}\right) .{ }^{14}$ We denote $V_{i}\left(a_{i}, a_{j}, b_{i}, b_{j}\right)$ the expected payoffs obtained by Worker $i$ when undertaking the second period project, $\forall i \neq j$ and $(i, j) \in\{1 ; 2\}^{2}$.

Given that workers assess each others' abilities as Bayesian inferers, we may wonder if allowing workers to communicate will lead agents to eliminate their learning biases and cooperate efficiently. ${ }^{15}$ The result captured in Proposition 2 shows that such conjecture is not verified, an ETE being impossible to achieve.

Definition 1 Under Assumption 3, a $P B E$ of the revelation game is $A^{*} \equiv$ $\left(a_{1}^{*}, a_{2}^{*}, b_{1}^{*}, b_{2}^{*}\right)$ that solves $(1)$ and $(2)$ :

(1) $\max _{a_{i} \in S} V_{i}\left(a_{i}, a_{j}^{*}, b_{1}^{*}, b_{2}^{*}\right), \forall i \neq j,(i, j) \in\{1 ; 2\}^{2}$.

(2) $\max _{b_{i} \in B} V_{i}\left(a_{1}^{*}, a_{2}^{*}, b_{i}, b_{j}^{*}\right), \forall i \neq j,(i, j) \in\{1 ; 2\}^{2}$.

Where $V_{i} \equiv 1_{N T} E_{i, S}\left[q_{i} \mid \sigma_{i i}, a_{j}\right]+1_{T} E_{i, S}\left[\eta_{i}\left(a_{i}, a_{j}\right)\left(q_{i}+q_{j}\right) \mid X_{j, 1}, \sigma_{i i}, a_{j}\right]$

We denote $1_{T}\left[1_{N T}\right]$ the indicator function that takes value one for $b_{1}=$ $b_{2}=T\left[\left(b_{1}, b_{2}\right) \neq(T, T)\right]$.

A $P B E$ is defined for a given contract function $\eta: x \mapsto \eta(x)$, where $x \in\{B ; G\}^{4}$ and $\eta(x) \in[0,1]$.

Proposition 2 There exist no Perfect Bayesian Equilibria $(P B E)$ that implement the ETO.

Workers are unable to reach the ETO because they have an incentive to reveal themselves as being high-ability workers in order to obtain a higher share of the group outcome. These incentives to lie implies that truthful telling is costly to achieve. Indeed, workers tell the truth in equilibrium only if the allocation rule of the group outcome is a fixed rule that is not contingent on $\left(a_{1}, a_{2}\right)$, i.e. $\eta\left(a_{1}, a_{2}\right)=\bar{\eta}$. However, fixed allocation rules do not provide the adequate incentives for workers to form teams since then high-performance

\footnotetext{
${ }^{13}$ The set of possible messages being the set of types, we can use the Revelation Principle and conclude that our results continue to hold for any message space. The Revelation Principle can be applied to our model since it can be represented as a normal form game of a static Bayesian game.

${ }^{14}$ We denote $\eta_{i}\left(a_{11}, a_{12}, a_{21}, a_{22}\right)$ the share of the group outcome obtained by Worker $i$.

${ }^{15}$ This would be the case when teams are formed whenever $\gamma \geq 1$.
} 
- Team formation decision

- A manager is hired
- Payoffs for the project(s)

selected at $\mathrm{t}=0$

- The manager decides the allocation rule of the team outcome
-Team formation decision
- Payoffs for the project(s) selected at $\mathrm{t}=1$ '

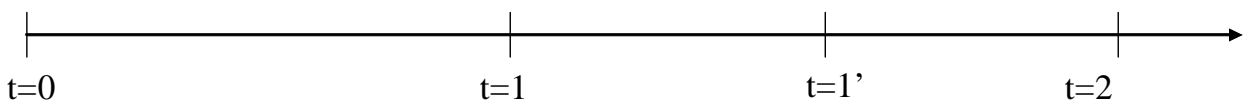

Figure 2: Timeline for the manager's game when a manager is hired at $t=0$.

workers will perceive their team rewards as being insufficient. In the case of fixed allocation rules the ETO is not attainable even in the presence of complete information. ${ }^{16}$

\section{Team managers}

\subsection{A model for team managers}

We consider a situation in which a third agent called a manager has the possibility to observe workers' performances. The manager is assumed to update workers' abilities without biases. This assumption is in agreement with the motivational explanation underlying biased self-attribution that is discussed in the introduction. ${ }^{17}$

\section{Definition 2 A manager is an agent that is able to observe team workers' performances without biases. \\ The manager is assumed to observe workers' performances without costs.}

The manager is paid a proportion $(\xi>0)$ of the total payoffs of coworkers' projects in the second period. The timing of the game is described as follows and represented in Figure 3.

At $t=0$, workers decide simultaneously whether to be involved in an individual or a team project rewarded according to equal splitting. They decide as well whether to hire a manager or not. If workers decide to hire a manager and the manager accepts the offer, the game continues as described below. At $t=1$, workers receive the payoffs of the first period project and the manager decides the allocation rule for the team project undertaken in the second period. This is equivalent to say that the manager has the full bargaining power. At $t=1^{\prime}>1$, workers decide whether to continue with the first period project or undertake another project. If workers decide not to hire a manager, the game becomes the one presented in Section 3. It is straightforward to see that

\footnotetext{
${ }^{16}$ The proof of this result is trivial and is available upon request.

${ }^{17}$ Agents are considered to feel better-off when learning positively about themselves. In the model considered in this section, the manager does not learn about himself since he is not involved in team production.
} 
if no bribery is possible, an ETE is attainable in this game. ${ }^{18}$ In the absence of bribery, the following strategies define a truthful telling $P B E$ : a manager is hired, the manager pays workers based on their true relative ability (that is the relative ability as perceived by the manager) and workers form teams whenever $\gamma \geq 1$. A truthful telling equilibrium (TTE) is such that all the information is revealed in equilibrium. ${ }^{19}$ This occurs if workers truthfully reveal their perceived performances $\left(a_{i}=\sigma_{i} \equiv\left(\sigma_{i i}, \sigma_{i j}\right), i \neq j\right)$. In that case, workers are able to recover the true information about their performances and this implies that learning biases are fully recognized. This $P B E$ holds as long as the manager has an interest to participate, that is $\xi>\hat{\xi} .{ }^{20}$ We provide in the next proposition a rationale for the existence of managers by establishing the conditions for the existence of the truthful telling $P B E$ previously mentioned. Managers prevent team conflicts by designing contracts based on informed and objective beliefs about workers' abilities. Managers possess an informational rent that is the result of their ability to provide unbiased assessments about workers' abilities. The main difference with the situation considered in Section 2 is that one of the agent (the manager) involved in the team has complete information at $t=1$. Workers 1 and 2 only observe correctly their coworker's performance whereas the manager observes team members' performances accurately.

As long as $\xi$ can be taken sufficiently close to 0 , the presence of a manager is optimal for any of the situations in which an ETE is not achievable. That is, as stated in Proposition 3, if $\hat{\xi}=0$ a manager is hired whenever $\gamma \phi<\frac{2 \hat{q}_{G}}{q_{B}+\hat{q}_{G}}$ $\left(\frac{\gamma}{\phi}<\frac{2 \hat{q}_{G}}{q_{B}+\hat{q}_{G}}\right)$.

Proposition 3 For $\gamma \phi<\frac{2 \hat{q}_{G}}{q_{B}+\hat{q}_{G}}\left(\frac{\gamma}{\phi}<\frac{2 \hat{q}_{G}}{q_{B}+\hat{q}_{G}}\right)$, a manager is hired with a strictly positive maximum rent increasing in the level of synergies $(\gamma)$ and in the level of coworkers' biases $(p)$.

For $\gamma \phi \geq \frac{2 \hat{q}_{G}}{q_{B}+\hat{q}_{G}}\left(\frac{\gamma}{\phi} \geq \frac{2 \hat{q}_{G}}{q_{B}+\hat{q}_{G}}\right)$ an ETE can be reached by using a simple equal sharing rule $\left(\eta=\frac{1}{2}\right)$ so that managers will not be hired in that

\footnotetext{
${ }^{18}$ Bribery is possible if a worker is able to pay the manager in order to change his release of the worker's ability.

${ }^{19}$ In a context in which bribery is possible, the conditions for the implementation of the $E T O$ are more difficult to meet. If it was not the case, managers could reject the bribery offer. Bribery increases the cost of hiring a manager whereas the benefits of his presence are at most the same. The gains of engaging a manager are maximum when the ETO can be implemented due to the presence of a manager. This happens when no bribery is possible but may not happen when opportunities for bribery exist. As a result, if $\gamma$ or $p$ are not sufficiently high, managers may not be hired in the presence of bribery for $\gamma \phi<\frac{2 \hat{q}_{G}}{q_{B}+\hat{q}_{G}}$ $\left(\frac{\gamma}{\phi}<\frac{2 \hat{q}_{G}}{q_{B}+\hat{q}_{G}}\right)$.

${ }^{20}$ We denote $\hat{\xi} 2 \gamma \phi q^{*}$ the revenue associated to the manager's outside option, where $2 \gamma \phi q^{*}$ is the expected aggregate outcome for the second period when workers decide to continue with the team project.
} 
case. We derive in Appendix $B$ the contracts that lead to the highest workers' expected payoffs for $\gamma \phi<\frac{2 \hat{q}_{G}}{q_{B}+\hat{q}_{G}}\left(\frac{\gamma}{\phi}<\frac{2 \hat{q}_{G}}{q_{B}+\hat{q}_{G}}\right)$. These contracts are respectively the rigid allocation rule $\left(e . g . \eta=\frac{1}{2}\right)$ in the absence of a revelation game and contracts $\left(C_{T T E, \frac{1}{2}}^{1}\right),\left(C_{T T E}^{2}\right)$ and $\left(C_{T T E}^{3}\right)$ if the revelation game is implemented. ${ }^{21}$ In the absence of a communication game, workers decide to hire a manager as long as $\xi \leq 1-\chi(\gamma, \phi, p)$, where $\chi(\gamma, \phi, p)=$ $p_{B B} \frac{q_{B}}{q^{*}}\left[(1-p)^{2}+\frac{1-(1-p)^{2}}{\gamma \phi}\right]+\left(p_{G G}+p_{G B} \gamma \phi\right) \frac{q_{G}}{q^{*}}$ and $\frac{\partial \chi(\gamma, \phi, p)}{\partial \gamma}<0, \frac{\partial \chi(\gamma, \phi, p)}{\partial p}<$ 0 . We call $2[1-\chi(\gamma, \phi, p)] \gamma \phi q^{*}$ the maximum rent of the manager. If contracts $\left(C_{T T E, \frac{1}{2}}^{1}\right),\left(C_{T T E}^{2}\right)$ and $\left(C_{T T E}^{3}\right)$ are available, the maximum rents for the manager are respectively:

$$
\begin{aligned}
& 2\left[1-\chi_{1}(\gamma, \phi, p)\right] \gamma \phi q^{*} \text { where: } \chi_{1}(\gamma, \phi, p)=\chi(\gamma, \phi, 0) \\
& 2\left[1-\chi_{2}(\gamma, \phi, p)\right] \gamma \phi q^{*} \\
& 2\left[1-\chi_{3}(\gamma, \phi, p)\right] \gamma \phi q^{*} \text { where: } \\
& \chi_{2}(\gamma, \phi, p) \equiv \frac{p_{B B} q_{B}}{q^{*}}\left[(1-p)^{2}+\frac{1-(1-p)^{2}}{\gamma \phi}\right]+\left(p_{G G} \frac{q_{G}}{q^{*}}+p_{G B}\right) \frac{q_{B}+q_{G}}{q^{*}} \\
& \chi_{3}(\gamma, \phi, p) \equiv \frac{p_{B B} q_{B}}{q^{*}}\left[\left(1-p^{2}\right)+p_{B B} \frac{p^{2}}{\gamma \phi}+p_{B G}\right]+\left(p_{G G}+p_{G B}\right) \frac{q_{G}}{q^{*}}
\end{aligned}
$$

It is easy to see that these maximum rents are increasing in both $\gamma$ and $p$.

Proposition 3 stresses how the objectivity of managers can be rewarded in equilibrium. The manager is hired if the level of synergies is not too high, that is for $\gamma \phi<\frac{2 \hat{q}_{G}}{q_{B}+\hat{q}_{G}}\left(\frac{\gamma}{\phi}<\frac{2 \hat{q}_{G}}{q_{B}+\hat{q}_{G}}\right)$, but his rent is increasing in $\gamma$ in this interval. The rent of managers is increasing in the synergy parameter since the presence of managers allows more teams to be formed. The more team formation is valued, the more team managers earn in equilibrium. Another reasonable result is that managers' pay increases as coworkers' cognitive biases increase. This is the case because managers' earnings depend on their informational advantage compared to coworkers. The more frequently workers overestimate their ability the more often team managers have an informational rent. As a result, the manager's informational rent and then his pay are increasing in $p$. In our model, there exists an incentive for team managers to maintain workers' biased self-attribution at a high level in order to maximize their informational rent. This behavior of managers is a limitation to the process of debiasing coworkers that adds to the individual's psychological cost of overcoming one's own biases.

\subsection{Team management when observing coworkers' performances is costly}

Proposition 3 is based on the fact that a team manager can costlessly observe coworkers' performances. We can extend our initial model by considering the case in which managers observe workers' performances at a cost $c>0$. In that case, at $t=1$ managers will decide whehter to observe workers' performances or not.

\footnotetext{
${ }^{21}$ The definition of the different contracts are provided in Appendix B. Team contracts are analyzed in details in Corgnet (2006a).
} 


\section{Assumption 2 (Costs of observing coworkers' performances)}

We assume that either the manager observes the performances of both workers at $t=1$ or he does not observe any performances.

We consider that observing coworkers' performances is performed at a cost $c>0$.

\section{Assumption 3 (Structure of synergies)}

We consider the possibility for the formation of inefficicent teams. In particular, we assume that forming a team of bad performances workers at $t=1\left(X_{1,1}=X_{2,1}=B\right)$ is inefficient. That is, if workers choose to form a team when $X_{1,1}=X_{2,1}=B$, they will receive the payoff $v\left(X_{1,1}+X_{2,1}\right)$, where $v<1$ with probability $\omega$ and they will receive the payoff $\gamma\left(X_{1,1}+X_{2,1}\right)$ with probability $(1-\omega)$.

As long as the gains in terms of increased cooperation are sufficiently high, even managers suffering costs of gathering information may be hired in equilibrium.

Proposition 4 Even if a manager observes workers' performances at a cost $c>0$, he will be hired in equilibrium as long as $c \leq 2 \omega(\gamma-v) p_{B B} q_{B}$.

In Proposition 4, we show that managers are hired in equilibrium as long as the cost of observing workers' performances is not too high compared to the benefits of observing performances. The benefits associated to observing workers' performances depend on the likelihood of inefficient team formation $\left(\omega p_{B B}\right)$ and on the maginitude of the inefficiency of teams formed by bad performances workers $\left(2(\gamma-v) q_{B}\right)$. Managers do not have incentives to observe workers' performances in equilibrium when $c>0$ if teams are always efficient $(\gamma=v)$. In that case team workers will anticipate that the manager will not observe workers' performances and they will decide not to hire a manager at $t=0$. To the contrary, if $c \leq 2 \omega(\gamma-v) p_{B B} q_{B}$ then team workers know that managers will observe performances in equilibrium. In that case, workers know that hiring a manager at $t=0$ will make possible the formation of any efficient team if the manager decides at $t=1$ to reward workers according to their true relative performances. ${ }^{22}$ As a result, hiring a manager is going to increase workers' expected payoffs with respect to any of the contracts considered in Appendix $B$. This is the case since there exist no contracts that allow for the formation of all the efficient teams when $\gamma \phi<\frac{2 \hat{q}_{G}}{q_{B}+\hat{q}_{G}}$.

\section{Discussion}

In this paper we developed a model of team formation in which workers are learning about their ability on a specific task. Backed by extensive psychological evidence, we considered the case in which workers are learning positively

\footnotetext{
${ }^{22}$ An inefficient team occurs with probability $\omega$ when workers performing badly in the first period decide to work together. Any other team is efficient.
} 
about themselves. In that context efficient teams are not always formed. This is the case because self-serving workers process information differently and hold different beliefs about workers' abilities. As a result, workers have private information about the ability of their coworkers. However, workers are not willing to inform their talented coworkers since then they would receive a lower share of the team outcome. We then explored the possibility of hiring a team manager in order to reduce the inefficiency in teams. We assumed that managers had the ability to observe workers' performances objectively. ${ }^{23}$ Team managers were then able to design team contracts based on true workers' abilities. This implied the existence of an equilibrium in which workers learn correctly about themselves and always form efficient teams. We also showed that managers would be hired in equilibrium even if observing workers' performances is costly.

As a result, we expect self-managed teams to be more commonly observed in contexts in which workers have low degrees of self-serving biases. In particular, cultural differences in the way people learn about themselves have been documented by psychologists. Japanese appear to be more self-critical than US and Canadian citizens (Kitayama et al. 1997, Heine et al. 1999, Heine, Kitayama, and Lehman 2001). In agreement with our model is the observation that the Japanese society characterized by self-criticism rather than self-serving attribution is associated with a corporate culture based on the intensive use of self-managed teams (Haitani 1990, Koike 1988).

In general, we expect autonomy in teams to be more detrimental as workers are learning intensively about their abilities. We expect self-managed teams to perform better when the team task leads to unambiguous feeback. Indeed, there exists evidence that individidulas' self-serving biases are stronger as the outcome of the task is more difficult to assess (Farh and Dobbins 1989, Huber 1991, Audia and Brion 2006). This is the case because individuals can more easily distort ambiguous information. We then predict that autonomy in teams will lead to higher performances in the case of teams involved in routine tasks associated with little learning and unequivocal feedback compared to creative team tasks involving extensive learning and ambiguous feeback. This implication of our model is in opposition to the analysis developed in the literature on self-managed teams that stresses how autonomy in teams should be more beneficial for creative and conceptual tasks than for routine tasks (Manz and Stewart 1997, Stewart and Barrick 2000). These authors argue that autonomy facilitates communication, flexibility, and conflict resolution so that creative and knowledge tasks that are more demanding in these dimensions are expected to benefit more extensively from self-leadership than routine tasks. However, the meta-analytic review undertaken by Stewart (2006) supports the reverse empirical implication as it is expected under our current framework. Then, we can regard workers' self-serving biases as a psychological limitation to increased autonomy in teams.

\footnotetext{
${ }^{23}$ There exists evidence that objectivity evaluations of subordinates is particularly relevant in identifying outstanding managers (Tan and Jamal 2001).
} 


\section{Appendices}

\section{Appendix A}

Comments on the assumptions. Instead of assuming perfect observability of coworkers' performances, it may appear more natural to consider that workers learn more about their partner when they work as a team. We can study the case in which workers are able to observe others' performances only when they form a team. This leads to a framework in which workers may decide to hide bad news about their abilities in order to signal themselves as being high-ability coworkers. In this setting the teams ine fficiency result remains valid for any of the equilibria of the game. This is the case since the conditions for team formation at $t=0$ crucially depend on the conditions for team formation at $t=1$ when a team has been formed at $t=0$. Since these conditions do not change with respect to the benchmark model, the conditions for team formation at $t=0$ are not modified. The analysis of this game is available in an extended version of this paper that is available upon request.

Concerning the risk neutrality assumption, we have to mention that taking into account risk aversion is likely to strengthen our results. The idea is that, as selfserving biases increase, the uncertainty about team continuation at $t=1$ rises. As a result, the negative impact of self-serving attribution on workers' cooperation is likely to be higher for risk averse agents.

Instead of assuming the presence of a learning by doing effect $(\phi)$, we can consider a fixed $\operatorname{cost} C>0$ incurred for shifting from the individual [team] project to the team [individual] project at $t=1$. The analysis of this game is available in an extended version of this paper that is available upon request. We show that the main results of our paper are not modified. The analysis of this game is available in an extended version of this paper that is available upon request.

We consider in our model a situation in which workers have the possibility to leave the team at $t=1$. However, there exist cases in which agents may attempt to commit at $t=0$ to continue with the project started in the first period. We have to stress that commitment at $t=0$ may be broken at $t=1$ by one of the two workers. In our framework commitment is not credible as it happens in many real life situations in which an exante agreement can be broken without further costs.

\section{Appendix B}

In the next proposition we derive, assuming a team has been formed at $t=0$, the contracts that are most likely to lead to team formation when $\gamma \phi<\frac{2 \hat{q}_{G}}{q_{B}+\hat{q}_{G}}$. These contracts are defined below and compared in Proposition 5. Similar contracts can be defined if a team has not been formed at $t=0$ by substituting $\phi$ by $\frac{1}{\phi}$ in the definitions of contracts $\left(C_{T T E}^{2}\right)$ and $\left(C_{T T E}^{3}\right)$. For $\gamma \phi<\frac{2 \hat{q}_{G}}{q_{B}+\hat{q}_{G}}$ we know that contracts based on fixed allocation rules cannot ensure team formation whenever $\gamma \geq 1$. We then consider contingent contracts and analyze the truthful telling $P B E$ associated to these contracts. We use the set $S^{\prime}$ defined as follows:

$$
S^{\prime} \equiv\left\{\begin{array}{l}
(q, r, q, r) \forall(q, r) \in S,(G, B, k, l) \forall(k, l) \in S \hat{A}(G, B) \\
(m, m, B, G) \forall m \in\{B, G\}
\end{array}\right\}
$$


Contract $\left(C_{T T E, \bar{\eta}}^{1}\right)$ is defined by the following system of equations:

$\left(C_{T T E, \bar{\eta}}^{1}\right) \Leftrightarrow\left\{\eta(i, j, k, l)=\bar{\eta}, \forall(i, j, k, l) \in S^{2}\right.$

$C_{T T E, \bar{\eta}}^{1}$ is the contract associated to the TTE derived in Proposition 4. It is such that allocation rules are independent of the signals revealed by workers at $t=1$. This contract leads to team formation for $\gamma \phi \geq \frac{2 q_{G}}{q_{B}+q_{G}}\left[\frac{\gamma}{\phi} \geq \frac{2 q_{G}}{q_{B}+q_{G}}\right]$ for $\bar{\eta}=\frac{1}{2}$.

Contract $\left(C_{T T E}^{2}\right)$ is defined by the following conditions:

$$
\left(C_{T T E}^{2}\right) \Leftrightarrow\left\{\begin{array}{l}
\eta_{G B G B} \in\left[\frac{q_{G}}{\gamma \phi\left(q_{B}+q_{G}\right)}, 1-\frac{q_{B}}{\gamma \phi\left(q_{B}+q_{G}\right)}\right], \eta_{G B G G}=\eta_{G B G B} \\
\left(\eta_{G B B B}, \eta_{G B B G}, \eta_{B B B G}\right) \in A^{3}, \text { where } A \equiv\left[0, \frac{1}{2 \gamma \phi}[\right. \\
\eta_{B G B G} \in\left[\frac{q_{B}}{\left(q_{B}+q_{G}\right) \gamma \phi}, 1-\frac{q_{G}}{\gamma \phi\left(q_{B}+q_{G}\right)}\right], \eta_{G G B G}=\eta_{B G B G} \\
\left(\eta_{G G G G}, \eta_{B B B B}\right) \in B^{2}, \text { where } B \equiv\left[\frac{1}{2 \gamma \phi}, 1-\frac{1}{2 \gamma \phi}\right] \\
\forall(i, j, k, l) \notin S^{\prime}, \eta_{i j k l}=0
\end{array}\right.
$$

Contract $\left(C_{T T E}^{2}\right)$ is such that allocation rules depend on the signals revealed by coworkers at $t=1$. In particular, considering $\gamma \phi<\frac{2 \hat{q}_{G}}{q_{B}+\hat{q}_{G}}$, the share of the group outcome given to the first worker is higher [lower] than equal splitting since $\frac{q_{G}}{\gamma \phi\left(q_{B}+q_{G}\right)}>\frac{1}{2}\left[1-\frac{q_{G}}{\gamma \phi\left(q_{B}+q_{G}\right)}<\frac{1}{2}\right]$ for $\left(X_{1,1}, X_{2,1}\right)=(G, B)[(B, G)]$. This contingent contract associated with full revelation of information in equilibrium allows workers to be rewarded based on their true relative ability. However, this contract does not permit teams to be formed when both workers receive a bad signal and at least one of them suffers from self-serving biases. This is the case since truthful revelation is not a possible equilibrium when $\gamma \phi<\frac{q_{B}+3 q_{G}}{2\left(q_{B}+q_{G}\right)}\left[\frac{\gamma}{\phi}<\frac{q_{B}+3 q_{G}}{2\left(q_{B}+q_{G}\right)}\right]$ if teams are formed for both $\sigma \equiv\left(\sigma_{1}, \sigma_{2}\right) \in \Sigma$ and $\left(X_{1,1}, X_{2,1}\right) \in V$. We denote $\Sigma \equiv\{(G, B, B, G) ;(G, B, B, B) ;(B, B, B, G)\}$ and $V \equiv\{(G, B) ;(B, G)\}$. In order to ensure team formation for $\left(X_{1,1}, X_{2,1}\right) \in V$, we have to prevent team formation for $\sigma \in \Sigma$ by taking $\eta_{G B B G}, \eta_{G B B B}$ and $\eta_{B B B G}$ sufficiently low, that is inferior to $\frac{1}{2 \gamma \phi}$.

Contract $\left(C_{T T E}^{3}\right)$ is defined for $\gamma \phi \geq \frac{q_{B}+3 q_{G}}{2\left(q_{B}+q_{G}\right)}$ as follows.

$$
\left(C_{T T E}^{3}\right) \Leftrightarrow\left\{\begin{array}{c}
\eta_{G B G B} \in\left[\frac{q_{G}}{\gamma \phi\left(q_{B}+q_{G}\right)}, 1-\frac{1}{2 \gamma \phi}\right] \\
\eta_{B G B G} \in\left[\frac{1}{2 \gamma \phi}, 1-\frac{q_{G}}{\gamma \phi\left(q_{B}+q_{G}\right)}\right] \\
\eta_{G B G G}=\eta_{G B B B}=\eta_{G B G B}, \eta_{G G B G}=\eta_{B B B G}=\eta_{B G B G} \\
\left(\eta_{G G G G}, \eta_{B B B B}\right) \in B^{2}, \text { where } B \equiv\left[\frac{1}{2 \gamma \phi}, 1-\frac{1}{2 \gamma \phi}\right] \\
\eta_{G B B G} \in\left[0, \frac{1}{2 \gamma \phi}\left[, \forall(i, j, k, l) \notin S^{\prime}, \eta_{i j k l}=0\right.\right.
\end{array}\right.
$$

Contract $\left(C_{T T E}^{3}\right)$ depends, similarly to contract $\left(C_{T T E}^{2}\right)$, on the signals revealed by coworkers at $t=1$. Contract $\left(C_{T T E}^{3}\right)$ is defined for $\gamma \phi \geq \frac{q_{B}+3 q_{G}}{2\left(q_{B}+q_{G}\right)}$ whereas contract $\left(C_{T T E}^{2}\right)$ is implementable for any $\gamma \geq 1$. The reason is that for $\gamma \phi \geq \frac{q_{B}+3 q_{G}}{2\left(q_{B}+q_{G}\right)}$, contract $\left(C_{T T E}^{2}\right)$ can be improved by taking $\eta_{B B B G}=\eta_{B G B G}$ and $\eta_{G B B B}=$ $\eta_{G B G B}$ since then teams can be formed for both $\sigma \in\{(G, B, B, B) ;(B, B, B, G)\}$ and $\left(X_{1,1}, X_{2,1}\right) \in\{(G, B) ;(B, G)\}$. However, contract $\left(C_{T T E}^{3}\right)$ does not ensure team formation for any $\gamma \phi \geq \frac{q_{B}+3 q_{G}}{2\left(q_{B}+q_{G}\right)}$ since teams are not formed when both workers receive a bad signal and both workers exhibit self-serving learning. The three 
contracts previously defined do not strictly dominate each other, choosing the best contract depends on the level of synergies and on the level of learning biases. This result is stated in Proposition 5, where the Best contract is defined as the contract implementing the highest coworkers' expected aggregate welfare in equilibrium.

Contracts that lead to the highest coworkers' expected payoffs for $\gamma \phi<\frac{2 \hat{q}_{G}}{q_{B}+\hat{q}_{G}}$ are as follows.

i) For $\gamma \phi<\frac{q_{B}+3 q_{G}}{2\left(q_{B}+q_{G}\right)}\left[\gamma \phi \geq \frac{q_{B}+3 q_{G}}{2\left(q_{B}+q_{G}\right)}\right]$ and $p_{G}<\frac{\left(2 p-p^{2}\right) p_{B}}{2}\left[p_{G} \geq \frac{p^{2} p_{B}}{2}\right]$, $\left(C_{T T E, \frac{1}{2}}^{1}\right)$ is the Best contract.

ii) For $\gamma \phi<\frac{q_{B}+3 q_{G}}{2\left(q_{B}+q_{G}\right)}$ and $p_{G} \geq \frac{\left(2 p-p^{2}\right) p_{B}}{2},\left(C_{T T E}^{2}\right)$ is the Best contract.

iii) For $\gamma \phi \geq \frac{q_{B}+3 q_{G}}{2\left(q_{B}+q_{G}\right)}$ and $p_{G} \geq \frac{p^{2} p_{B}}{2},\left(C_{T T E}^{3}\right)$ is the Best contract.

We know from Proposition 4 and the definitions above that contract $\left(C_{T T E, \frac{1}{2}}^{1}\right)$ leads to individual work when the signals received are asymmetric whereas team formation is obtained in that case for the two other contracts. The three contracts are not equivalent since contracts $\left(C_{T T E}^{2}\right)$ and $\left(C_{T T E}^{3}\right)$ are preferred when selfserving biases are not too high, that is respectively when $p(2-p) \leq \frac{2 p_{G}}{p_{B}}$ and $p \leq$ $\sqrt{\frac{2 p_{G}}{p_{B}}}$. An increase in coworkers' learning biases $(p)$ does not affect the probability $\left(p_{G G}+p_{B B}\right)$ with which a team is formed under contract $\left(C_{T T E, \frac{1}{2}}^{1}\right)$ whereas it decreases the frequency with which teams are formed under contracts $\left(C_{T T E}^{2}\right)$ and $\left(C_{T T E}^{3}\right)$. In the next corollary, we derive from Propositions 4 and 5 the conditions under which contracts stating fixed allocation rules are dominated by contracts based on allocation rules that are contingent on coworkers' revealed signals.

\section{Appendix C}

Proof of Proposition 1. The proposition follows from the conditions for team formation at $t=1$ under the relative ability allocation rule. By comparing expected payoffs associated to team projects and individual projects, it is easy to see that teams are formed at $t=1$ after a team has [not] been formed at $t=0$ if $\gamma \geq \phi\left[\frac{1}{\phi}\right]$. As a result, at $t=0$, teams are formed whenever $\gamma \geq 1$. This is equivalent to say that the ETO is achieved.

Proof of Proposition 2. We denote $\sigma_{1} \equiv\left(\sigma_{11}, \sigma_{12}\right)$ and $\sigma_{2} \equiv\left(\sigma_{21}, \sigma_{22}\right)$, and we take $p_{G}\left[p_{B}\right]$ to be the expected probability given information at $t=0$ that $X_{i, 1}=G\left[X_{i, 1}=B\right], \forall i \in\{1 ; 2\}$.

i) First, we show that an ETE is only possible if it is a truthful telling equilibrium $(T T E)$. A truthful telling $P B E$ is such that in equilibrium workers reveal their observed signals: $a_{i}=\sigma_{i}$ so that beliefs in equilibrium are such that $P\left[\left(X_{1,0^{\prime}}, X_{2,0^{\prime}}\right)=\left(a_{12}, a_{21}\right)\right]=1$. Assume the payoff at $t=0^{\prime}$ is $\left(X_{1,0^{\prime}}, X_{2,0^{\prime}}\right)=$ $(B, B)$ and both agents suffer from self-serving learning (i.e. $\sigma_{1}=(G, B)$ and $\left.\sigma_{2}=(B, G)\right)$. The ETO is implemented if team formation is obtained for any $\gamma \phi \geq 1\left[\frac{\gamma}{\phi} \geq 1\right]$. We argue that these conditions for team formation can be obtained only if workers' beliefs converge in the revelation game. As long as agents' beliefs diverge, Proposition 2 shows that an ETE is no attainable. The only way beliefs 
can converge in the case mentioned above $\left(\left(X_{1,0^{\prime}}, X_{2,0^{\prime}}\right)=(B, B) ; \sigma_{1}=(G, B)\right.$; $\left.\sigma_{2}=(B, G)\right)$ is when both workers tell the truth. In that case, both workers learn that they performed poorly in the first period. As a result, an ETE has to be truthful telling.

ii) Second, we prove that a truthful telling PBE cannot implement the ETO. This is the case since efficient teams $(\gamma \geq 1)$ may not be formed when a team has [not] been formed at $t=0$ for $\gamma \phi<\frac{2 q_{G}}{q_{B}+q_{G}}\left[\frac{\gamma}{\phi}<\frac{2 q_{G}}{q_{B}+q_{G}}\right]$. A TTE must be such that workers cannot be worse-off by playing $a_{i} \neq \sigma_{i}$ whether a team has been formed at $t=0$ or not. These conditions generate a system of 8 inequations that lead to the following unique solution $\eta_{(i j k l)}=\bar{\eta}, \forall(i, j, k, l) \in S^{2}$. The lower bound for achieving team formation is then $\gamma \phi \geq \frac{2 q_{G}}{q_{B}+q_{G}}\left[\frac{\gamma}{\phi} \geq \frac{2 q_{G}}{q_{B}+q_{G}}\right]$ and corresponds to the case $\bar{\eta}=\frac{1}{2}$. Since $\frac{2 q_{G}}{q_{B}+q_{G}}>1$, we get the inefficiency result stated in Proposition 2 .

Proof of Proposition 3. The first part of the proposition follows from simple algebra comparing the expected utility of a worker in the different cases. We consider the case of symmetric contracts (each worker pays the same amount to the manager) so that the expected utility of the two coworkers is the same. This is the most favorable situation for the manager since it is the case in which the expected payoffs for the coworker with the lowest expected welfare are maximum. Under symmetric contracts the necessary conditions for hiring a manager are less demanding than for any other contracts.

The second part of the proposition is proved in the main text

Proof of Proposition 4. A manager will be hired in equilibrium if he decides to observe workers' performances at a $\operatorname{cost} c>0$. A manager will observe workers' performances in equilibrium if and only if:

$$
\begin{aligned}
& \xi\left(2 \gamma q^{*} \omega-c\right) \geq \xi\left(2 p_{G B} \gamma\left(q_{B}+q_{G}\right)+2 p_{G G} \gamma q_{G}+2 p_{B B} v q_{B}\right) \omega \\
& \Leftrightarrow c \leq 2 \omega(\gamma-v) p_{B B} q_{B} .
\end{aligned}
$$

Under this condition, the manager does not have incentives to deviate since not observing workers' performances leads to a lower expected payoff. As a result, if $c \leq 2 \omega(\gamma-v) p_{B B} q_{B}$ a manager is hired in equilibrium and this manager decides to observe workers' performances at a $\operatorname{cost} c>0$. 


\section{References}

Alchian, A., H. Demsetz. 1972. Production, information costs, and economic organization, American Economic Review, 62: 777-795.

Audia, P., S. Brion. 2006. Reluctant to change: self-enhancing responses to diverging performance measures, forthcoming in Organizational Behavior and Human Decision Processes.

Bénabou, R., J. Tirole. 2002. "Self-confidence and personal motivation." Quarterly Journal of Economics, 117(3): 871-915.

Box, G., G. Tiao. 1973. Bayesian inference in statistical analysis, Reading MA: Addison Wesley.

Bradley, G. W. 1978. "Self-serving biases in the attribution process: a reexamination of the fact or fiction question." Journal of Personal and Social Psychology, 36: 56-71.

Che, Y., S. Yoo, 2001. "Optimal incentives for teams." American Economic Review, 91: 525-541.

Cooper, A., Woo, C., W. Dunkelberg. 1988. "Entrepreneurs' perceived chances for success." Journal of Business Venturing, 3: 97-108.

Dumaine, B. 1990. Who needs a boss? Fortune, May, 52-60.

Eaton, B. C., A. Hollis. 2003. "Private information and teamwork." University of Calgary Working Paper.

Farh, J. L., G. H. Dobbins. 1989. Effects of self-esteem on leniency bias in self-reports of performance-A structural equation model analysis, Personnel

Psychology, 42: 835-850.

Felson, R. B. 1984. "The effects of self-appraisals of ability on academic performance." Journal of Personality and Social Psychology, 47: 944-952.

Fiske, S. T., S. E. Taylor. 1991. Social cognition, McGraw-Hill, 2nd edition.

Florida, R., M. Kenney. 1991. "Transplanted organizations: the transfer of Japanese industrial organizations to the US." American Sociological Review, 56: 381-398.

Gervais, S., I. Goldstein. 2006. "The effects of biased self-perception in teams." The Fuqua School of Business Working Paper.

Goodman, P., Devadas, R.and T. Hughson. 1988. Groups and productivity: analyzing the effectiveness of self-managing teams. In J.P. Campbell and R.J. Campbell (Eds.), Productivity in organizations. San Francisco, CA: Jossey-Bass, 295-327.

Greenwald, A. G. 1980. "The totalitarian ego: fabrication and revision of personal history." American Psychologist, 35: 603-618.

Griffin, D., A. Tversky. 1992 "The weighing of evidence and the determinants of overconfidence." Cognitive Psychology,24: 411-435.

Haitani, K. 1990. "The paradox of Japan's groupism: threat to future competitiveness?" Asian Survey, 30: 237-250.

Hamilton, B., Nickerson, J., and H. Owan. 2003. "Team incentives and worker heterogeneity: an empirical analysis of the impact of teams productivity and participation." Journal of Political Economy, 111(3): 465-497 
Heine, S. J., Lehman, D. R., Markus, H. R., and S. Kitayama. 1999. "Is there a universal need for positive self-regard?" Psychological Review, 106(4): 766-794.

Heine, S. J., Kitayama, S., D. R. Lehman. 2001. "Cultural differences in selfevaluation: Japanese readily accept negative self-relevant information." Journal of Cross-Cultural Psychology, 32(4): 434-443.

Holmstrom, B. 1982. "Moral hazard in teams." Bell Journal of Economics, 13: 324-340.

Huber, V. L. 1991. Comparison of supervisor-incumbent and female-male multidimensional job evaluation ratings, Journal of Applied Psychology, 76: 115-121.

Ichniowski, C., K. Shaw and G. Prennushi. 1997. The effects of human resource management practices on productivity, American Economic Review 87: 291-313.

Ishida, J. 2005. "Incentives in academics: collaboration under weak complementarities." OSIPP Discussion Paper.

Itoh, H. 1991. "Incentives to help in multi-agent situations." Econometrica, 59(3): 611-636.

Kandel, E., E. P., Lazear. 1992. "Peer pressure and partnerships." Journal of Political Economy, 100: 801-817.

Kitayama, S., Markus, H. R., Matsumoto, H., Norasakkunkit V. 1997. "Individual and collective processes in the construction of the self: Self-enhancement in the United States and self-criticism in Japan." Journal of Personality and Social Psychology, 72: 1245-1267.

Koike, K. 1988. Understanding industrial relations in modern Japan, New York, St Martin's.

Korner, I. 1950. "Experimental Investigation of some aspects of the problem of repression: repressive forgetting." $\mathrm{N}_{0} .970$. New York, NY: Bureau of Publications, Teachers' College, Columbia University.

Kuiper, N. A., P. A. Derry. 1982. "Depressed and nondepressed content selfreference in mild depression." Journal of Personality, 50: 67-79.

Kuiper, N. A., M. R. McDonald. 1982. "Self and other perception in mild depressives." Social Cognition, 1: 233-239.

Kuiper, N. A., Olinger, L. J., McDonald M. R., B. F. Shaw. 1985. "Self-schema processing of depressed and nondepressed content: the effects of vulnerability on depression." Social Cognition; 3: 77-93.

Lawler, E., Mohrman, S. and Ledford, G. 1995. "Creating high performance organizations: practices and results of employee involvement and total quality management in Fortune 1000 companies. San Francisco: Jossey Bass."

Lee, P. M. 1997. Bayesian statistics: an introduction, 2nd edition, London: Arnold.

Lewinsohn, P. M., Mischel, W., Chaplin, W., R. Barton. 1980. "Social competence and depression: the role of illusory self-perceptions" Journal of Abnormal Psychology, 89: 203-212.

Manz, C. C., G. L. Stewart. 1997. "Attaining flexible stability by integrating total quality management and socio-technical systems theory." Organization Science, 8: $59-70$. 
Miller, D. T., M. Ross. 1975. "Self-serving biases in the attribution of causality: fact or fiction?" Psychological Bulletin, 82: 213-225.

Mischel, W., Ebbesen, E. B., A. R. Zeiss. 1976. "Determinants of selective memory about the self." Journal of Consulting and Clinical Psychology, XLIV: 92103.

Nisbet, R. E., L. Ross. 1980. Human inference: strategies and shortcomings of social judgments, Englewood Cliffs, NJ: Prentice-Hall.

Osterman, P., 1994, How common is workplace transformation and who adopts it? Industrial and Labor Relations Review, 47: 173-188.

Pronin, E., Lin, D. Y., L. Ross. 2002. "The bias blind spot: perceptions of bias in self versus others." Personality and Social Psychology Bulletin, 28: 369-381.

Rabin, M. 2002. "Inference by believers in the law of small numbers", Quarterly Journal of Economics, 117(3): 775-816.

Rotemberg, J. 1994. "Humans relations in the workplace." Journal of Political Economy, 102: 684-717.

Repenning, N., J. Sterman. 2002. "Capability traps and self-confirming attribution errors in the dynamics of process improvement." Administrative Science Quarterly, 47: 265-295.

Salanié, B. 1997. The Economics of contracts: a primer, Cambridge Massachusetts: MIT Press.

Schinski, M., Kugler, A., W. Wick. 1998. "Perceptions of the academic Finance profession regarding publishing and the allocation of credit in coauthorship situations." Financial Practice and Education, 8(1): 60-68.

Silverman, I. 1964. "Self-esteem and differential responsiveness to success and failure." Journal of Abnormal and Social Psychology, 69: 115-119.

Stewart, G. 2006. A meta-analytic review of relationships between team design features and team performance, Journal of Management 32 (1): 29-54.

Stewart, G. and M. Barrick. 2000. Team structure and performance: assessing the mediating role of intrateam process and the moderating role of task type. Academy of Management Journal, 43: 135-148.

Svenson, O. 1981. "Are we all less risky and more skillful than our fellow drivers?" Acta Psychologica, 47: 143-148.

Tan, H. and K. Jamal. 2001. "Do auditors objectively evaluate their subordinates' work?" The Accounting Review, 76 (1): 99-110.

Van den Steen, E. 2004. "Rational overoptimism (and Other Biases)." American Economic Review, 94: 1141-1151.

Zuckerman M. 1979. "Attribution of success and failure revisited or, : the motivational bias is alive and well in attribution theory." Journal of Personality, 47: 245-285. 